$\xi=1$ 国

\title{
EMG-Based Spasticity Robotic Arm Forupper Arm Fatigue Identification
}

\author{
Abdul Malik Mohd Ali ${ }^{1 *}$, Syed Faiz Ahmed ${ }^{1}$, Athar Ali ${ }^{1}$, M. Kamran Joyo ${ }^{1}$, Kushairy A. Kadir ${ }^{1}$, Radzi Ambar ${ }^{2}$ \\ ${ }^{1}$ Universiti Kuala Lumpur British Malaysian Institute, , Malaysia \\ ${ }^{2}$ Universiti Tun Hussein Onn, Johor, Malaysia. \\ *Corresponding author E-mail:*E-mail:amalik@unikl.edu.my.
}

\begin{abstract}
Electromyogram (EMG) signal reflect the electrical activity of human muscle and contains information about the structure of muscle. Furthermore, motor unit action potential (MUAP) is the results from spatial and temporal summation of difference muscle fibers of a single motor. The EMG signal results, in turn is from the summation of different MUAPs which are sufficiently near the recording electrode. EMG signal can identify the differences between signals from bicep, triceps and forearms during exercise. Raw data from the experiment is vital to assist physiotherapy to understand when the subject fatigue of noise high pick signal during rehabilitation. Several normal subjects were selected to perform experiments to understand the pattern of fatigue in early state, middle stage and last stage of exercises.
\end{abstract}

Keywords: Electromyogram (EMG), Rehabilitation, Robotic and Sensor.

\section{Introduction}

Based on Oxford (2016), physiotherapy is the treatment or way to recover any disease, injury, or deformity by physical methods such as massage, heat treatment, and exercise rather than by drugs or surgery. Physiotherapists is a way that have been used to help people affected by injury, illness or disability through some movement and exercise, manual therapy, education and advice. This process can keep up wellbeing for individuals of any age, helping patients to manage pain and prevent disease. This kind of technique is

a science-based profession and takes a 'whole person' way to deal with wellbeing and health, which incorporates the patient's general way of life. Generally, physiotherapy is

Practiced by physiotherapists. It was introduced on late of 19th century where nurses were performed massage to the patients Nowadays, special design exercise and equipment was built up as a branch of rehabilitative health to help patients recover their physical abilities (J. H. Burridge and A. M. Hughes, 2010). the device will be focus on arm rehabilitation. The patients can monitor the progress of the exercise and the data can be logging into the Excel on daily or weekly basis. There are seven stages of stroke recovery in way to recover the patient ability after stroke. This recovery task which is also known as Brunnstrom Approach was introduced in 1960's by Signe Brunnstrom (an occupational and physical therapist from Sweden). These stages were developed to determine how motor control can be recover throughout the body after suffering a stroke. The stages that involve in this robot arm for rehabilitation process which relates with Brunnstrom Approach is in stages 3 to 5. For stage 3, the effected arm that was damaged in stroke survivors was start recover but he need someone to move the effected arm. In this stage, the movement is limit between some ranges due to the severe of spasticity due to feeling of unusually stiff, pulled, or tight muscles. Any exercises that want to use to recover the effected arm must maintain the ability for patient range of motion and doing daily task to the arm so that it will avoid from bad effect to the patient. Figure 1.2.1 shows some level or range of ability for stroke survivors can be achieve. The fourth stage will be used when the spasticity is decrease. In this stage, it will focus on to gain the strength and improve muscle control. Figure 1.2.2 shows the exercise to gain strengthen and improve muscle control. Next, stage five is the complex movement combinations which the small amount of spasticity is left. The survivors can now move the muscles more coordinated and allow the voluntary movement to become more complex. The exercise that was provide is by repeat the movement of arm frequently in daily activity like eat, drink, iron cloth and others (The Brunnstrom Stages of Stroke Recovery, 2017). A multitude of recovery technologies has been introduced in the most recent decade. These technologies are used for patient to improve their armhand performance after stroke. Stroke have been increased consistently and putting at high pressure on health system for some decades, as the result in raising of the demands for cost-effective for the treatments. The role of this kind of technologies is training to improve arm function in activities of daily lives. This also will reduce the depend on man power (J. H. Burridge and A. M. Hughes, 2010). Figure 1.2.3 shows some example of robot arm for rehabilitation that was been in the hospitality. This project is developed to give automated physiotherapy for arm rehabilitation. The controller is set to give automated help to the patient to help them to track a coveted movement direction. All the direction for the rehabilitation process is required for the recovery task in a precise and concentrated way. This recovery task is intended to guarantee concentrated repeated movement that requires psychological preparing. This movement will burn into a microcontroller of the robotic arm to make all the movement is follows the recovery task. The effectiveness and feasibility of this controller have 
been presented by using some sensors that can measure the participate performance which then the data will extract by using signal processing method to present the data in clinical requirement

\section{Methodology}

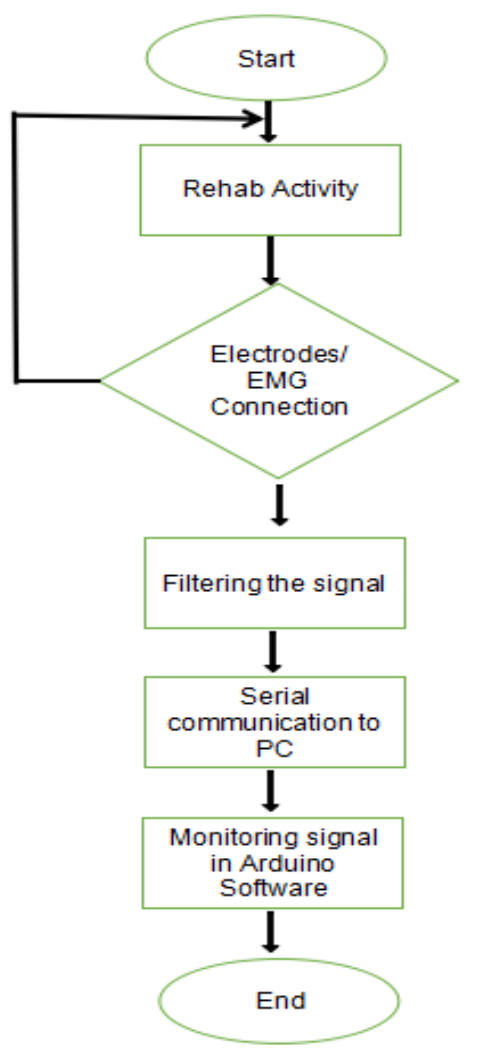

Fig. 1: Flowchart of the SRA system.

Experiment has been conducted to show the effectiveness of the proposed Spasticity Robotic Arm (SRA). Fig.1 depicts the flowchart of the experiment steps to determine the effectiveness of the device by EMG data collection of a subject arm movements. As shown in the figure, the experiment involved a pre-determined rehabilitation movements using the SRA. The subject of SRA is attached with EMG electrodes. These electrodes will provide the EMG signals vital for the movement analysis. The data is filtered, and conveyed to an Arduino microcontroller for data processing. The processed data is transmitted to a personal computer (PC) for monitoring and analyses purposes. The experiment involved five (5) steps that are described below:

Step 1: Preparation. Initially, the subject placed his/her arm on the SRA. During this condition, EMG electrodes were attached on the arm at three (3) locations: biceps, triceps and brachioradialis muscles.

Step 2: Rehab Activity. As the subject was a normal person, the rehabilitation activity involved lifting a $1 \mathrm{~kg}$ dumbbell and hold it for a few minutes. For actual patient, lighter object can be used or activities that do not involve object lifting are recommended to prevent aggravating injury.

Step 3: EMG electrodes- The sensor will be attach on bicep to recoded the Myopath activity during Hyperemia in bicep brach and triceps during exercise. Using the electrode channel with is positive (red), negative(black) and ground (green)

Step 4: The signal from the three channel electrode produce multi noise, because of that the processing part is very vital to make signal clear and solid Fig.7. The smooth and filtering noise will be apply to make raw data clear using Savitzky-Golay method. On 500 point window. Step 5: The Serial port on computer will be receive after filtering data and process in microcontroller brain system using Arduino microcontroller base system.

\subsection{The Development of Spasticity Robotics Arm (SRA)}

The development of robotic arms shown in Fig. 2. The robot have two degree of freedom (DOF). Point $\mathrm{A}$ is the base of this robot placement, Point $\mathrm{B}$ is shoulder angle and point $\mathrm{C}$ is the wrist. The limitation movement is only $\mathrm{x}$ and $\mathrm{y}$ axis on two DOF. Each DOF have 3 axis with is $\mathrm{x}, \mathrm{y}$ and $\mathrm{z}$. The bicep axis starting from $\mathrm{x} 0, \mathrm{y} 0$ and $\mathrm{z} 0$ and the wrist is $\mathrm{x} 1, \mathrm{y} 1$ and $\mathrm{z} 1$.

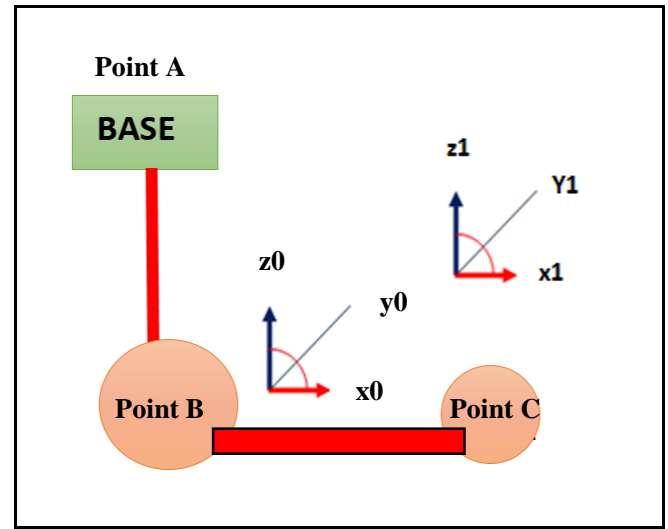

Fig. 2: The axes and 2 DOF of robotic arms

The design of this project must be lightweight and potable because to carry burden of the upper arms subject. In order of that aluminium plate and polymer was selected in fabrication of this robot design shown in Fig. 3. The heat-shrink insulation cover to warp the aluminium part of $U$ shape, to make material water vaporproof. The U shape and on this Fig.3 was make to support the elbow and bicep subject during forearms flexion and extension during exercise. The size of the $U$ shape in this illustration is $12.5 \mathrm{~cm} \times 15.5 \mathrm{~cm}$ and cover by heat shrink insulation. The part $\mathrm{A}$ is the $\mathrm{u}$ Shape and part be is holder of the U shape to attach to the mechanical movement stand show in Fig.4.

The complete cycle of this exercise is 20 minute, during on that period of exercise the subject was sweating and discomfort the select of material can make the process of exercise success.
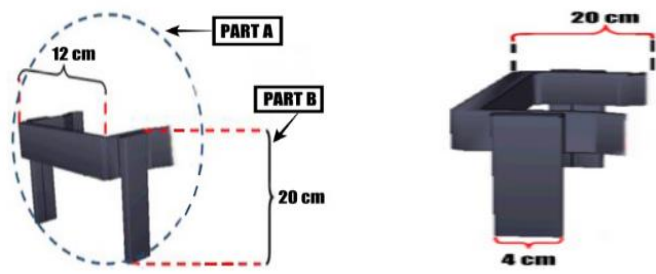

Fig. 3: 3 Dimension of the upper elbow part

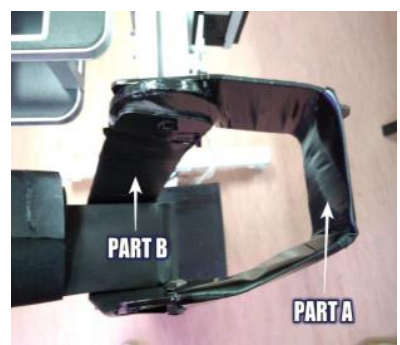

(a) Side view

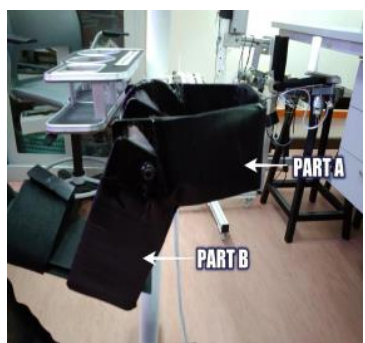

(b) Top view
Fig. 4: Actual image of the upper elbow part

Fig. 5 shows the illustration of U Shape bar attach on the mechanical robotic stand. In this figure also shown the part A and part B placement. The part A is the electrical controller linear actuator 
box and the part B is cover and mechanical forward and reverse switch. The limitation movement of this robot shown in table 1.

\begin{tabular}{|l|c|}
\hline \multicolumn{1}{|c|}{ Upper arms body } & Degree of freedom (DOF) \\
\hline Elbow & $0^{\circ}$ to $90^{\circ}$ \\
\hline Wrist & $0^{\circ}$ to $35^{\circ}$ \\
\hline
\end{tabular}

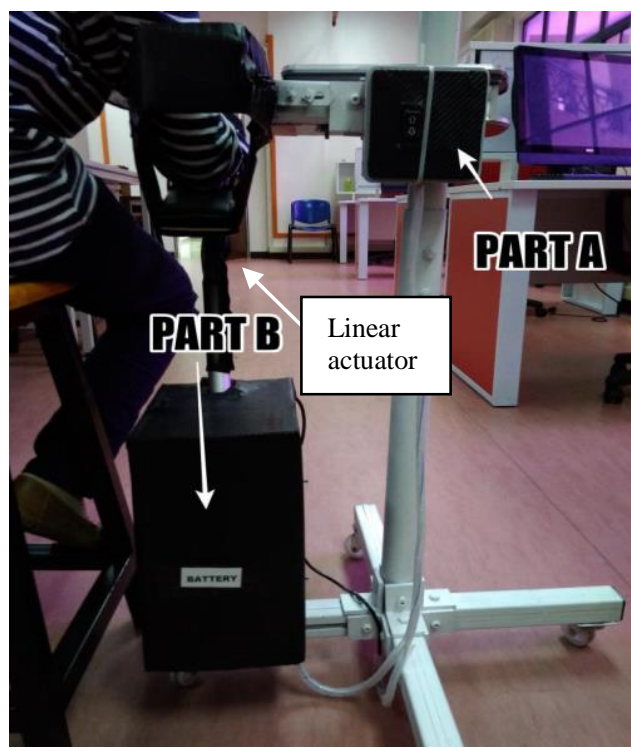

Fig. 5: Design of the Spasticity Robotic Arm

The movement of this robot control by linear actuator mechanical electrical system. The voltage of this actuator is 9 to 12 Volt direct current (DC). The length of the actuator motor is $200 \mathrm{~mm}, 200 \mathrm{~N}$, this actuator can carry $20 \mathrm{Kg}$ (heavy duty linear actuator). The material of the actuator is aluminium alloy and working frequency is $20 \%$ [17]. The stroke shaft of the linear actuator is $150 \mathrm{~mm}$ with $200 \mathrm{~N}$.
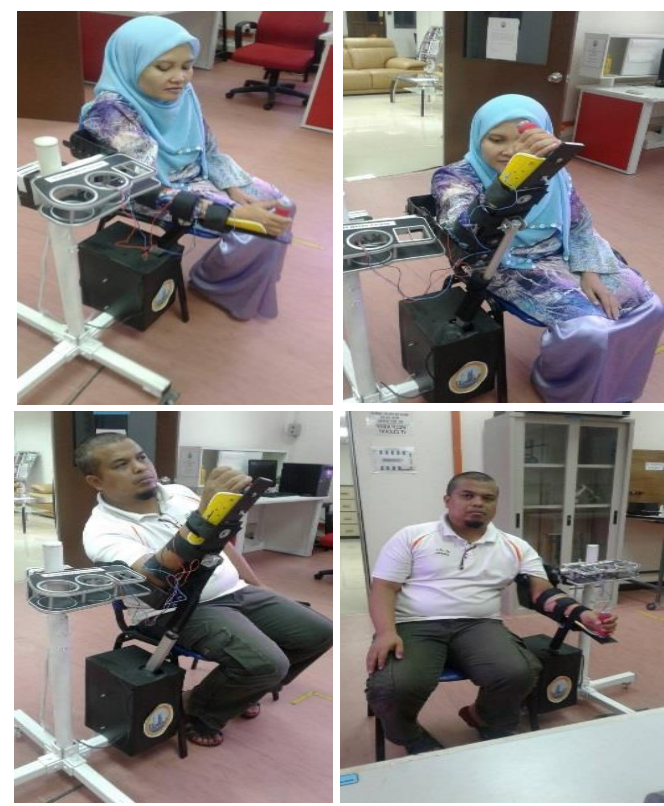

Fig. 6: Female and male subjects experimenting with the SRA using left and right arm

\section{Experimental Setup, Result and Discussion}

\subsection{Robotic Hand Training}

In the experiment, a normal subject perform exercise to measure the muscle strength from bicep brachii, tricep brachii, ewtensor carpi ulnaris and brachioradialis. Firstly, the subject will be asked to do exercises involving four different types of hand reaches. Secondly, a normal subject will be asked to Flexion and extension 1000gram weight in 1 minute. Nine normal adult subjects (ages 18-25, 5 male and 4 female) using right arms. The subject was apply Modified Ashworth Scale (MAC) [12] method exercise. The exercise was control angle movement for bicep, elbow and forearms. The result shown in table 2. Subject one first time perform experiment and second subject were asked to make exercise using dumbbell (reach up and down right arms) in 5 minute before perform experiment.

Table 2: Demographic data the recruited subject before fatigue

\begin{tabular}{|c|c|c|c|c|c|}
\hline $\begin{array}{c}\text { Sub- } \\
\text { ject no }\end{array}$ & $\begin{array}{c}\text { Na- } \\
\text { ture of } \\
\text { subject }\end{array}$ & Gender & $\begin{array}{c}\text { Dominant } \\
\text { hand }\end{array}$ & Age & $\begin{array}{c}\text { Time } \\
\text { since } \\
\text { fatigue }\end{array}$ \\
\hline 1 & $\mathrm{H}$ & $\mathrm{M}$ & $\mathrm{R}$ & 19 & 10 \\
\hline 2 & $\mathrm{AE}$ & $\mathrm{M}$ & $\mathrm{R}$ & 20 & 4 \\
\hline 3 & $\mathrm{H}$ & $\mathrm{F}$ & $\mathrm{R}$ & 19 & 9 \\
\hline 4 & $\mathrm{H}$ & $\mathrm{F}$ & $\mathrm{R}$ & 21 & 6 \\
\hline 5 & $\mathrm{AE}$ & $\mathrm{F}$ & $\mathrm{R}$ & 25 & 3 \\
\hline 6 & $\mathrm{H}$ & $\mathrm{M}$ & $\mathrm{R}$ & 25 & 7 \\
\hline 7 & $\mathrm{AE}$ & $\mathrm{M}$ & $\mathrm{R}$ & 23 & 8 \\
\hline 8 & $\mathrm{H}$ & $\mathrm{F}$ & $\mathrm{R}$ & 24 & 8 \\
\hline 9 & $\mathrm{AE}$ & $\mathrm{M}$ & $\mathrm{R}$ & 19 & 7 \\
\hline
\end{tabular}

Abbreviations: Healthy (H), After exercise (AE), Left(L), right (R), female (F), male (M).

The experiment was focus on the mayopath area and study response of muscle during hyperemia and con contraction index (CI) between using Electromyogram. The parameter used to quantitative the muscle activation and coordination pattern of raw data. The processing frequency is $50 \mathrm{~Hz}$ to $100 \mathrm{~Hz}$ off-line process. The bipolar data processing is remove noise, rectification, smoothing and normalization the maximum value of EMG activation level of hyperemia upper arms. The two simple equation apply during collecting data shown in formula (1) and (2). The EMG activation level of a muscle was calculated by averaging the EMG envelope of the trial Equation 1 and Equation 2 shows a simple model of the EMG signal [29-30]

$$
\begin{gathered}
\mathrm{EMG}=1 / \mathrm{T} \int_{0}^{1} \underset{i}{E G_{i}(t) d t} \\
\mathrm{X}(\mathrm{n})=\sum \mathrm{h}(\mathrm{r}) \mathrm{e}(\mathrm{n}-\mathrm{r})_{=j}^{\mathrm{N}-1} \mathrm{w}(\mathrm{n})
\end{gathered}
$$

Where $x(n)$, modelled EMG signal, e(n),point processed represents the firing impulse, $h(r)$,represents the MUAP w(n),zero mean addictive white Gaussian noise and $\mathrm{N}$ is the number of motor unit firing and second equation was the EMG activation level of muscle i, EMG i(t) was the EMG envelope signal, and " $T$ " was the length of the signal. Fig. 7 representative EMG trials [30]. Fig.8 ( $\mathrm{a}$ and $\mathrm{b}$ ) shows the raw data input from two electrode attach on the bicep brachii and ground attach at tricep. The minimum time is 30 second and maximum time is 70 second. 


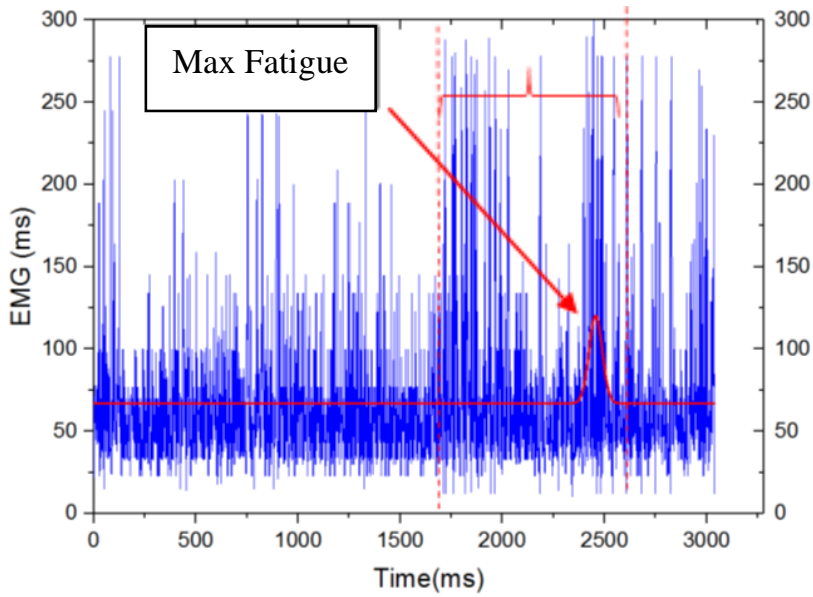

Fig. 7: Representative EMG trials of subject in training session (a) the evaluation (a horizontal task trial), (b) the illustration on the EMG triggering brachioradialis muscle (bicep) EMG signal.

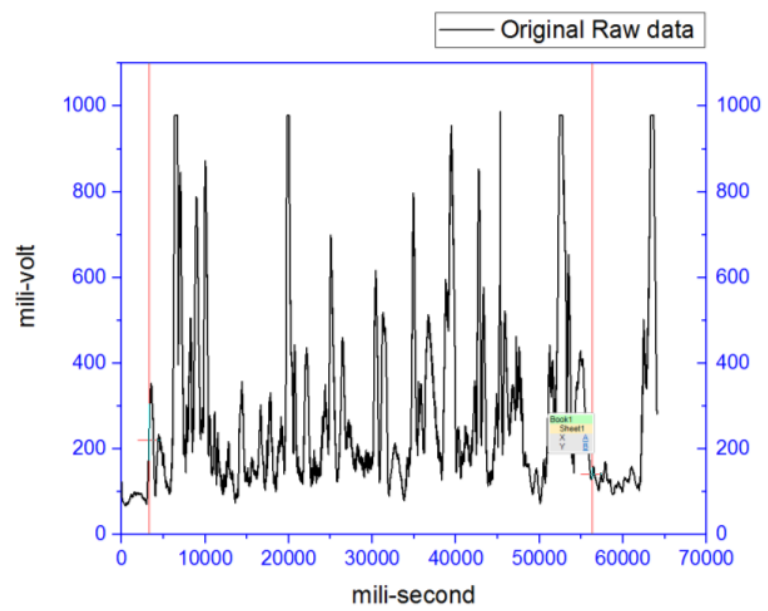

Fig. 8: Original Raw Data from Electromyogram.

Fig. 9 removing noise and smoothing by using Savitzky-Golary in 1000 point of window and $50 \mathrm{~Hz}$ frequency to measure fatigue of the tricep and bicep brachii. The sampling signal is $70000 \mathrm{~ms}$ after rectification.

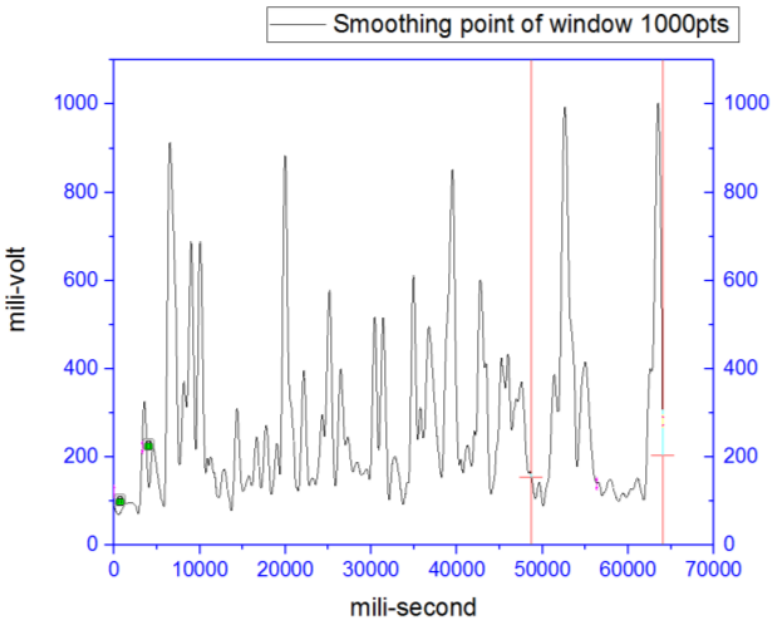

Fig. 9: 1000 pts point of window smoothing.

Fig. 10 after removing noise and smoothing by using SavitzkyGolary in 1000 point of window and $50 \mathrm{~Hz}$ to measure fatigue of the tricep and bicep brachii. Second is curve fitting method to understand value of fatigue level during exercise in model Gauss in position y0 ( $244.64746 \pm 1.60149)$, $\mathrm{xc}(63475 \pm 5.16675)$ is the sampling signal is $70000 \mathrm{~ms}$ after rectification.

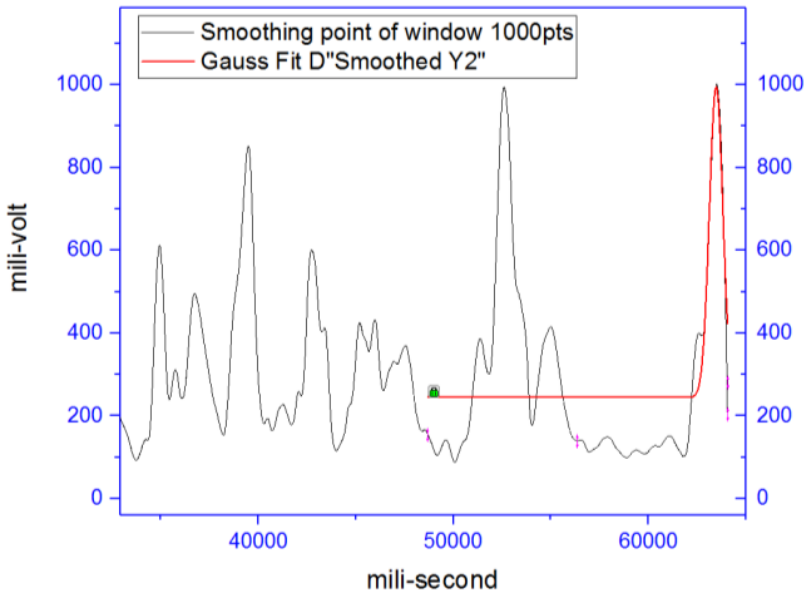

Fig. 10: Original Raw Data from Electromyogram and curve fitting method to understand value of fatigue level during exercise in model Gauss.

The smoothing data in $50 \mathrm{~Hz}$ filter frequency domain in Fig.11 removes low and high frequencies from the original signal. For the But for this graph, it will be afterward, because these filters remove low frequency components of a signal, and so they force the mean value to be zero or nearly zero. High frequency cutoff of band pass filter removes high frequency noise and prevents aliasing from occurring in the sampled signal.

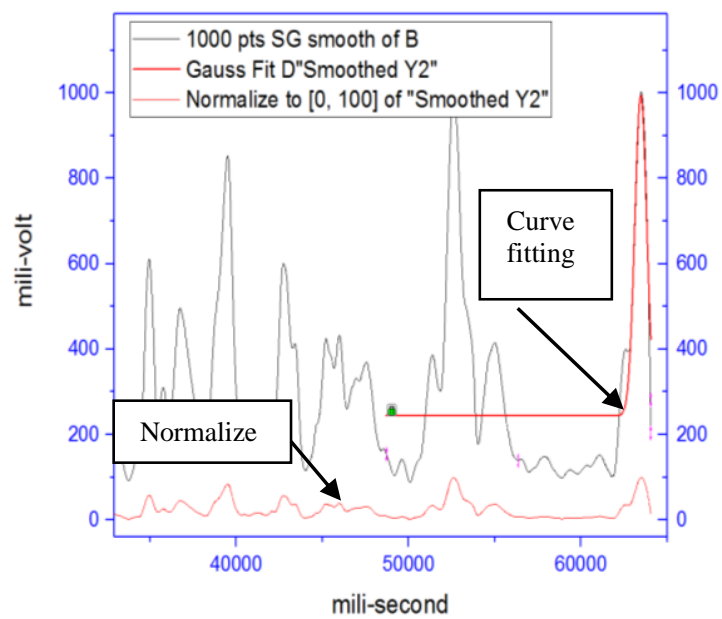

Fig. 11: Original Raw Data from Electromyogram and normalize to $(0,100)$ of smoothing method

\section{Conclusion}

In this experiment the monitoring and measurement of the hyperemia study can improve the exercise of the real stroke patient during exercise, the method of exercise can assist physiotherapy and researcher understand different input and output in real time data or off-line data. The standard Modified Ashworth Scale (MAC) is the benchmark this rehabilitation exercise to normal subject and stroke patient in future.

\section{Acknowledgement}

The author would like to take opportunity to express thank you to the volunteer and medical engineering student to help during this experiment and produce this paper.

\section{References}

[1] Oxford English Students Version Second Edition. (2011). Oxford: Oxford University Press.

[2] H. (n.d.). Retrieved April 30, 2017, from https://www.hindawi.com/ 
[3] The Brunnstrom Stages of Stroke Recovery. (2017, March 30). Re trieved May 1, 2017, from https://www.saebo.com/the-stages-ofstroke-recovery/

[4] J. H. Burridge and A. M. Hughes (2010). Potential for new technologies in clinical practice. Curr Opin Neurol, vol. 23, pp. 671-7.

[5] MOH Malaysia. National Health and Morbidity Survey 2011 Report: Institute of Public Health.

[6] L. R. (2016). The Medical Journal of Malaysia.

[7] Amal NM, Paramesarvathy R, Tee GH, Gurpreet K, Karuthan C. (2006). Revalence of Chronic Illness and Health Seeking Behaviour in Malaysian Population: Results from the Third National Health Morbidity Survey (NHMS III), 66(1): 36-41.

[8] MOH Malaysia. National Health and Morbidity Survey 2011 Report: Institute of Public Health.

[9] (n.d.). Retrieved April 15, 2017, from http://www.worldlifeexpectancy.com/

[10] McComas AJ. (1994). Medicine \& Science in Sports \& Exercise. Human neuromuscular adaptations that accompany changes in activity, 26, 1498-1509.

[11] A. A. Timmermans, H. A. Seelen, R. D. Willmann, and H. Kingma (2009). Technologyassisted training of arm-hand skills in stroke: concepts on reacquisition of motor control and therapist guidelines for rehabilitation technology design. J Neuroeng Rehabil, 6, 1.

[12] Farina, D., Merletti, R. (2000). Comparison of algorithms for estimation of EMG variables during voluntary isometric contractions. J Electromyogr Kinesiol, 10(5), 337-349.

[13] Ferdjallah, M., Wertsch, J.J., Shaker, R. (2000). Spectral analysis of surface electromyography (EMG) of upper esophageal sphincteropening muscles during head lift exercise. J Rehabil Res Dev, 37(3), 335-340.

[14] Ferdjallah, M., Wertsch, J.J., Shaker, R. (2000). Spectral analysis of surface electromyography (EMG) of upper esophageal sphincteropening muscles during head lift exercise. J Rehabil Res Dev, 37(3), 335-340.

[15] Bovend'Eerdt TJ, Newman M, Barker K, Dawes H, Minelli C, Wade DT. (2008). The effects of stretching in spasticity: A systematic review. Archives of Physical Medicine \&Rehabilitation, 89, 1395-1406.

[16] Grammaticos PC, Diamantis (2008), A Useful known and unknown views of the father of modern medicine, hippocrates and his teacher Democritus. Hell. J. Nucl. Med.11(1), pp. 2-4.

[17] Ashrafian H (2005), Herod the Great and his Worms. Journal of Infection., 51(1): 82-3.

[18] Pearce JM (1997), Johann Jakob Wepfer (1620-95) and cerebral haemorrhage. Journal of Neurology, Neurosurgery and Psychiatry, vol. 62 , no. 4 , pp. 387.

[19] Amene Saghazadehab Sina Hafizib Nima Rezaei, Inflammation in venous thromboembolism: Cause or consequence, Volume 28, Issue 1, September 2015, Pages 655-665

[20] Sun HwaLeeMD, PhDaSeong JongYunMDb Taking varenicline for smoking cessation: A rare cause of pulmonary thromboembolism with infarction Volume 35, Issue 7, July 2017, Pages 1037.e3 1037.e6

[21] Martin Bilodeau Marco Cincera, Bertr Arsenault Denis Grave Normality and stationarity of EMG signals of elbow flexor muscles during ramp and step isometric contractions Volume 7, Issue 2, June 1997, Pages 87-9.

[22] Trent J.HerdaaJorge M.ZunigabEric D.RyancClayton L.Camicd The influence of electromyographic recording methods and the inner ovation zone on the mean power frequency-torque relationships Volume 25, Issue 3, June 2015, Pages 423-430

[23] Furie B, Furie BC (2008), Mechanisms of thrombus formation. N Engl J Med. 359:938 -949.

[24] Handin RI (1994), Disorders of the platelet and vessel wall. In: Issen bacher KJ, Braundwell E, Wilson JD, et al, eds. Harrison's principles of internal medicine. 13th ed. New York: McGraw Hill, pp. 1798-803.

[25] V. Dietz, T. Sinkjaer, Spastic movement disorder: impaired reflex function and altered muscle mechanics, Lancet Neurol. 6 (2007) 725- 733. http://dx.doi.org/ 10.1016/S1474-4422(07)70193-X.

[26] J.W. Lance, Spasticity: Disorder of Motor Control, Year Book Medical Publishers, Chicago, 1980.

[27] S. Li, G.E. Francisco, New insights into the pathophysiology of post- stroke spasticity, Front. Hum. Neurosci. 9 (2015).

[28] A.Waninge, R.A.Rook , Feasibility, test-retest reliability, and inter rater reliability of the Modified Ashworth Scale and Modified Tardieu Scale in persons with profound intellectual and multiple disabilities
[29] M. B. I. Reaz, M. S. Hussain1 and F. Mohd-Yasin Techniques of EMG signal analysis: detection, processing, classification and applications 2006; 8(1): 11-35.

[30] X.L. Hu, K.Y. Tong ^, X.J. Wei, W. Rong, E.A. Susanto, S.K. Ho The effects of post-stroke upper-limb training with an Electromyogramphy (EMG)-driven hand robot

[31] B. Ashworth, Preliminary trial of carisoprodol in multiple sclerosis, Practitioner $\quad 192 \quad 540$ 542〈http://www.ncbi.nlm.nih.gov/pubmed/14143329〉.

[32] R.W. Bohannon, M.B. Smith, Interrater reliability of a modified Ashworth scale of muscle spasticity, Phys. Ther. 67 (1987) 206-207. http://dx.doi.org/10.1007/978- 1-4471-5451-8 105 .

[33] F. Biering-Sørensen, J.B. Nielsen, K. Klinge, Spasticityassessment: a review Spinal Cord Off, J. Int. Med. Soc. Paraplegia 44 (2006) 708-722. http://dx.doi.org/ 10.1038/sj.sc.3101928.

[34] B.D. Schmit, Y. Dhaher, J.P. Dewald, W.Z. Rymer, Reflex torque response to movement of the spastic elbow: theoretical analyses and implications for quanti- fication of spasticity, Ann. Biomed Eng. 27 (1999) 815-829. http://dx.doi.org/ 10.1114/1.234

[35] Ahmed, S. F. (2007, December). A new approach in Industrial automation application" Embedded system design for Injection Molding Machine". In Multitopic Conference, 2007. INMIC 2007. IEEE International (pp. 1-5). IEEE

[36] Ahmed, S. F., Desa, H., Azim, F., Surti, A., \& Hussain, W. (2013, April). Remote access of SCADA with online video streaming. In Computer Science \& Education (ICCSE), 2013 8th International Conference on (pp. 270-274). IEEE. 